\title{
Development of smooth finishes in electrostatic fluidized bed (EFB) coating process of high-performance thermoplastic powders (PPA $571 \mathrm{H}$ )
}

\author{
Massimiliano Barletta*, Annamaria Gisario, Stefano Guarino, Gianluca Rubino \\ University of Rome “Tor Vergata”, Department of Mechanical Engineering, Via del Politecnico, 1-00133 Rome, Italy
}

Received 12 June 2006; accepted 15 September 2006

\begin{abstract}
This paper deals with the analysis of the evolution of the surface morphology of metal substrates coated with high-performance thermoplastic powders, namely PPA $571 \mathrm{H}$, by using electrostatic fluidized bed (EFB) process. Attention has been particularly focused on the relationship between baking time and temperature of EFB coated substrates and the morphological characteristics of the resulting polymeric films.

First, thermal behaviour of PPA $571 \mathrm{H}$ polymeric powders was characterized by using standard calorimetric techniques. Accordingly, PPA 571 $\mathrm{H}$ melting kinetic was experimentally deduced. Based upon experimental findings, predictive analytical model was also developed and employed to trace 'iso-conversion' curves out.

Second, metal substrates, made from low carbon steel (AISI 1040), were EFB coated and baked at several baking time and temperatures. Combined analyses of scanning electron and confocal microscopes were led to measure the evolution of the films surface morphology under different baking conditions. Accordingly, a relationship between film morphologies and melting degree was sought. Consistent trends of roughness parameters versus baking parameters were found, with smoother finishes of the polymeric films being achieved for higher degrees of melting, that is, for higher baking temperature and time. Full maps and related analytical models of the finishing levels according to baking parameters were also built up, hence providing first useful indications to powder coaters on how to best deal with their settings.
\end{abstract}

(C) 2006 Elsevier B.V. All rights reserved.

Keywords: Fluidized bed coating; High-performance thermoplastic powder; Morphological characterization; Melting degree

\section{Introduction}

Since the 1970s, powder coaters have paid particular attention towards fluidized bed coating processes, being considered low cost and environmental friendly alternatives to traditional coating and painting processes [1-9]. Early on, fluidized bed processes were mostly in use to coat small batches of large metallic parts, which were first preheated at high temperature (at least $300-350^{\circ} \mathrm{C}$ ) and, then, dipped in the bed of fluidized powders [3-6], generally a thermoplastic polymer. Later, more sophisticated fluidized bed processes, based on electrostatic techniques, were adopted to coat also large volumes of small and complex shaped parts [7-9]. In that case, the coated parts had to be baked in order to melt the layers of electrostatically deposited powders and consolidate them in the form of a continuous film $[8,9]$. In recent times, fluidized bed coating has been successfully

\footnotetext{
* Corresponding author. Tel.: +39 0672597168; fax: +39062021351.

E-mail address: barletta@mail.mec.uniroma2.it (M. Barletta).
}

extended even in the application of thick functional films made from engineered polymers (PEEK, PEK, PPS, fluoro-organic polymers, etc.) for protection and insulation purposes [10-17].

Nevertheless, due to several alleged drawbacks, like the tricky procedures needed for process automation and control, the characteristic unevenness of coating thicknesses, the rather poor aesthetic aspect of manufactured goods, the need for large amounts of powders to run coating operations and the awkward colour change protocols, fluidized bed processes have always experienced difficulties with becoming well-liked as coating techniques [2].

Nowadays, due to the ever more strict environmental regulations, which prohibit and/or limit the employment of solventborne coatings, and to the firm requirements for dry coating techniques with faster 'cycle time' (just one coating step is required and no liquid should be evaporated during fluidized bed coating) and with minimum wastes to dump, renovated interest towards fluidized bed coating is taking place. Several research programs about the study of process settings and their relationship with active mechanisms [14-17], the experimen- 
tation of new coating materials [14], the introduction of new plant solutions $[15,16]$ and, above all, about the simulation, control and automation of fluidized bed coating [17] are currently in progress. Nonetheless, significant efforts, dealing with the comprehension of the bonds between coatings performance and fluidized bed and baking operational parameters, do still miss.

In this context, our paper is aimed at analyzing the relationship between morphological characteristics of EFB coated metal substrates and baking parameters after EFB coating process. In specific, this work is aimed at identifying the most promising baking conditions for the maximization of aesthetic performance of EFB deposited PPA $571 \mathrm{H}$ films. For the purposes of this study, thermal properties of PPA $571 \mathrm{H}$ were analyzed by differential scanning calorimetry. Full kinetic analyses were carried out through the execution of isothermal and dynamic runs. This way, the trends of melting degrees of PPA $571 \mathrm{H}$ according to temperature and time were experimentally and analytically calculated. Afterwards, low carbon steel substrates were EFB coated and resulting films were baked at several baking time and temperatures. Electron scanning and confocal microscopy was used to follow the evolution of film morphologies under different baking conditions (baking temperature and time). Consequently, the relationship between film morphologies and melting degrees was sought. Consistent trends of roughness parameters versus baking parameters were found. Smoother finishes of the polymeric films were achieved for higher degrees of melting, that is, when higher baking temperatures and times were set. Accordingly, full maps and related analytical models of the finishing levels versus baking parameters were also built up. A good fitting between analytical and available experimental data was found out, hence stating the reliability of the analyses led.

\section{Experimental}

\subsection{PPA 571 H powders}

PPA $571 \mathrm{H}$ supplied by Plascoat Systems Limited as finely divided powders was used as coating material. PPA $571 \mathrm{H}$ has been specifically designed to provide a long lasting, tough coating for exterior applications to mild steel, galvanised steel and aluminium. It is based on an alloy of acid modified polyolefins. Therefore, it is halogen-free and the combustion fumes are low in smoke and have a very low toxicity index. PPA $571 \mathrm{H}$ is resistant to stress cracking, adverse weather conditions, detergents, salt spray and typical airborne pollutants. The coating maintains excellent adhesion to the metal substrate without the need for a separate primer. The material also provides a good degree of electrical insulation, abrasion and impact resistance.

Previous papers [14,15] investigated the hydrodynamic behaviour of Plascoat PPA 571 powder in great detail. The distribution peak of the unsieved Plascoat PPA $571 \mathrm{H}$ powder lay in the range $100-150 \mu \mathrm{m}$, and its cumulative curve showed $95 \%$ of the grain size distribution to be below $250 \mu \mathrm{m}$. A minimum fluidization velocity of $0.0032 \mathrm{~m} / \mathrm{s}$ was measured. Bubbling regime was kept in an airflow range of $3.5-7 \mathrm{~m}^{3} / \mathrm{h}$, which meant superficial velocities varying in a range of 5-10 times the minimum fluidization velocity [14]. Employing airflows in the range between 8 and $12 \mathrm{~m}^{3} / \mathrm{h}$ meant that significant elutriation phenomena could occur [14].

\subsection{Metal substrates and surface preparation}

From 6 m long AISI 1040 low carbon content (0.43\%) steel rods, samples $60 \mathrm{~mm} \times 40 \mathrm{~mm} \times 4 \mathrm{~mm}$ were cut off. As well known, such material is widely used in several industrial segments as basis for fencing panels, sign posts, street furniture, public structures seating, pipes in general, garden furniture, battery boxes, and wirework. The steel substrates, before being coated with PPA $571 \mathrm{H}$, were submitted to a set of surface pretreatments in order to improve the adhesion of the coating on them. A vapour degreasing cleaning, employing common solvents to remove oil, grease, loose metal chips, and other contaminants from the surface, was followed by a zinc phosphating, in which both the coating weight and the crystal size were accurately controlled. An additional acid cleaning step was necessary when rust and scale had to be removed. Finally, a rinsing cycle was applied to flush away the remaining 'drag-out' from the previous bath and to neutralise the surface. Once all the impurities on the metal surface had been removed, the surface was conditioned so that the adhesion of the coating film would be optimal. Because it provides a uniform surface on the substrate resulting in the absence of flash rust, powdering and windowing, an iron phosphate was applied to provide the best basis for bonding the powder coating film to the metal surface.

\subsection{EFB coating process}

A cylindrical fluidized bed (tank) of PPA $571 \mathrm{H}$ powders, working in bubbling regime, was used for coating purposes (Fig. 1). A detailed description of the experimental apparatus can be found in several previous papers [14-17]. Here, it is worth remarking that the fluidized bed coating system is constituted of three different parts: (i) a fluidization column made from Plexiglas, $250 \mathrm{~mm}$ in diameter and $4 \mathrm{~mm}$ in wall thickness to provide enough rigidity; (ii) a porous plate distributor made from sintered bronze powders, $250 \mathrm{~mm}$ in diameter and $8 \mathrm{~mm}$ thick, able to sustain PPA $571 \mathrm{H}$ powders when the coating system is switched off and to permit the passage of the fluidization air when the coating system is switched on; (iii) a homogenization section able to ensure uniform distribution of the fluidization air to the fluidization column. A sliding vane rotary compressor Mapro, model 'Free-Oil 20', for flow rates from 3 to $20 \mathrm{~m}^{3} / \mathrm{h}$, pressures up to 0.9 bar relative and $1.5 \mathrm{~kW}$ as maximum power, was used to feed purified air flux lacking in oil and moisture into the fluidized bed, under strictly monitored process conditions. In fact, a standard flowmeter Kobold (model KSM-flow rate $0-35 \mathrm{~m}^{3} / \mathrm{h}$, provided with a $0-10 \mathrm{~V}$ dc output), and an inverter Mitsubishi model FR-S 540E feedback controlled were respectively used to read and control the current value of air flux, hence keeping it constant during the whole treatment. A set of pressure probes, a hygrometer and a set of thermocouples were also used to monitor the coating process and the environmental conditions.

The corona charging method, which makes use of a high voltage generator $(0-100 \mathrm{kV})$, was employed in order to bring 


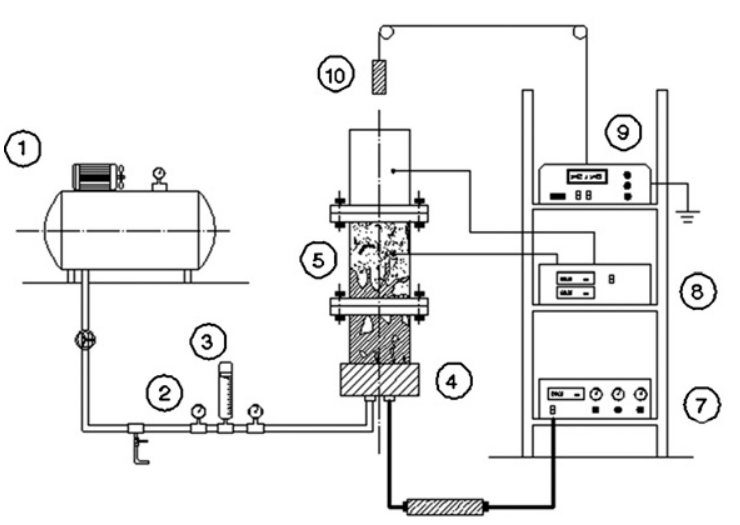

(6)

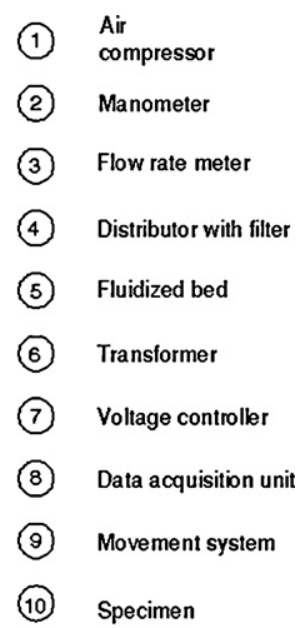

(1) Air

Fig. 1. Scheme of the EFB system.

an electrostatic charge (mostly negative) onto the PPA $571 \mathrm{H}$ powder particles through the intermediate process of creating oxygen ions. For such purpose, the present fluidized bed system incorporates a set of electrodes in the powder chamber beside the porous plate distributor, even though alternative solutions are possible. In EFB coating process, the upper part of the tank, halffilled with a certain volume of PPA $571 \mathrm{H}$ powders (static bed height of $230 \mathrm{~mm}$ ), is fluidized by ionized air from below. With the help of the transport air, the resulting electrically charged cloud of powder moves in the direction of the grounded metal substrate. As the charged particles come close to the substrate, electrostatic force causes the particles to be deposited on and adhere to the substrate when it is passed into or through the powder cloud or just hung in the cloud.

\subsection{Thermal analysis}

The thermal behaviour of PPA $571 \mathrm{H}$ powders was studied by using standard calorimetric techniques (Differential Scanning Calorimeter DSC Netzsch model DSC200PC). Dynamic scans with variable heating rates from 1 to $10^{\circ} \mathrm{C} / \mathrm{min}$ were aimed at individuating the melting (i.e., the crystallization) kinetic of the PPA $571 \mathrm{H}$ powders. A three phase temperature programs were employed during dynamic scans: an heating phase in which temperature was, generally, increased from $20^{\circ} \mathrm{C}$ up to, at least, $120^{\circ} \mathrm{C}$; an isothermal phase, in which the stabilization of the temperature was imposed for, at least, 5 min to handle the transition from the heating to the subsequent cooling phase; finally, a cooling phase in which a progressive cooling with the same rate of the heating phase was performed up to take the sample temperature to its starting value (i.e., around $20^{\circ} \mathrm{C}$ ). This quite articulated scanning program was chosen in order to overcome troubles typically associated with the scan of polymeric powders. In fact, during first heating, just the relaxation of the stresses induced on powders by manufacturing process as well as their rearrangements inside the crucible are mostly achieved. This way, during cooling phase or reheating of the same sample, the actual kinetic of the thermoplastic powders can be calculated, with the concurrent minimization of unpredictable deviations or anomalies and of external disturbances affecting the experimental procedure (Table 1).

\subsection{Experimental procedure}

The scheduled protocol during the execution of the experimental tests is reported hereafter:

1. The substrates surface was accurately cleaned and prepared for EFB deposition process according to indications reported in Section 2.2.

2. Once the substrates surface had been prepared, the EFB system was switched on. As a consequence, a cloud of charged particles rapidly rose from the bottom of the fluidization chamber.

3. The metal substrate was hung in a 'built ad hoc' holder and, then, dipped in the electrostatically charged cloud of PPA $571 \mathrm{H}$ particles inside the fluid bed. The longest side of metal substrates $(60 \mathrm{~mm})$ was located along the $z$-axis of the column to check the coating vertical uniformity. The substrate position in the bed was varied by activating a CNC system, which allowed the movement along the three axes to be controlled. The location of the substrate inside the column was kept constant during each experimental test.

4. Standard coating conditions $\left(6 \mathrm{~s}\right.$ exposure time, $9 \mathrm{~m}^{3} / \mathrm{h}$ airflow, and $65 \mathrm{kV}$ applied voltage) in EFB were used to perform all the deposition processes. Such choice was determined by several previous study about best settings of operational parameters during EFB coating process $[14,15]$.

Table 1

Typical properties of the powder

\begin{tabular}{ll}
\hline Properties & Values \\
\hline Coverage (100\% efficiency) & $3 \mathrm{~m}^{2} / \mathrm{kg}$ at $350 \mu \mathrm{m}$ \\
Particle size & $95 \%$ less than $250 \mu \mathrm{m}$ \\
Bulk density (at rest) & $0.40 \mathrm{~g} / \mathrm{cm}^{3}$ \\
Fluidizing characteristics & Excellent \\
Packaging & $20 \mathrm{~kg}$ cardboard boxes \\
\hline
\end{tabular}


Table 2

Experimental trials

\begin{tabular}{llllllll}
\hline Baking & \multicolumn{7}{l}{ Baking temperature $\left({ }^{\circ} \mathrm{C}\right)$} \\
time (min) & 100 & 110 & 130 & 150 & 170 & 200 & 230 \\
\cline { 2 - 7 } & & & & & 19 & 22 & 24 \\
\hline 5 & & & 11 & 16 & & 23 & \\
10 & & 4 & 12 & & 20 & & \\
15 & & 5 & 13 & 17 & & & \\
20 & & 6 & 14 & & 21 & & \\
25 & 1 & 8 & 15 & 18 & & & \\
30 & 2 & 9 & & & & & \\
35 & 3 & 10 & & & & & \\
40 & & 7 & & & & \\
45 & & & & & & & \\
\hline
\end{tabular}

5. Once coated, the substrate was removed from the fluid bed and picked up from the holder with the utmost care. A heating cycle with an electrical convective oven (Naddeo model RT 11) was applied to melt the coating and to obtain the best finish for the polymeric film EFB deposited onto the metal substrate. This way, the influence of baking temperature and time on the evolution of the surface morphology of the polymeric films was studied according to the experimental trials reported in Table 2 .

6. After being baked, each substrate was left to cool slowly in the oven without being moved. The amount of coating still clinging to the surface was, then, accurately measured by using the MEGACHECK 5F-ST instrument. To minimize the influence of coating thickness on morphological evolution of PPA $571 \mathrm{H}$ films, only the substrates coated with $400 \mu \mathrm{m}( \pm 40 \mu \mathrm{m})$ as coating thickness were considered for further processing. When applied films failed to agree to the above reported specification, the coated substrates were disregarded.

7. Finally, combined analyses of scanning electron microscope and non-contact profilometry were subsequently employed to study the evolution of surface morphology of the polymeric films according to baking parameters. The means of the experimental data were then calculated and reported. Measures of variability were reported in terms of standard deviation. A set of process maps was built in which the average roughness was reported in great detail by varying baking parameters.

\subsection{Surface topography and roughness measurements}

Images of film morphologies were obtained using a field emission gun scanning electron microscope (FEG-SEM Leo model Supra 35) using the 'in-lens detector'. The 3D morphology of the coatings was obtained with a Taylor Hobson surface topography system (model TalySurf CLI 2000) using a noncontact $300 \mu \mathrm{m}$ chromatic aberration length (CLA) HE gauge.

In comparison to conventional system, the CLA HE gauge offers superior imaging capability with improved resolution ( $10 \mathrm{~nm}$ and $0.4 \mu \mathrm{m}$ as vertical and lateral resolution, respectively). Scanning in three dimensions can be performed and the absence of contact between the gauge and the surface being mea- sured ensures the avoidance of any damages to the surface being measured. For the CLA profilometry, the substrates were located under the gauge and viewed optically, using the high resolution camera built into the surface topography system. This enabled the choice of both the measurement area and the rough focusing of the gauge. Using the CLA HE scanning mode, a number of patterns (1000), each $4 \mathrm{~mm}$ long, was recorded for each substrate so as to cover a representative area $\left(16 \mathrm{~mm}^{2}\right)$ of the entire surface structure. The surface morphology was then examined by using the TalyMap software release 4.0. As roughness indicators, standard amplitude parameters $R_{\mathrm{a}}$ and $S_{\mathrm{a}}$ were considered.

\section{Results and discussion}

\subsection{Crystallization kinetic of PPA 571 H powders}

Fig. 2 reports the experimental results of three DSC dynamic scans at variable heating rates from 1 to $10^{\circ} \mathrm{C} / \mathrm{s}$. Progressively higher heating rates caused a left shift of the melting peaks took place as result of the different thermal inertia phenomena involved [18]. The relaxation enthalpy peaks can be ascribed to the relaxation of stresses induced by manufacturing process into the PPA $571 \mathrm{H}$ powders as well as to the rearrangement of the powders inside the crucible during DSC tests. Crystallization peaks together with the full DSC scans at the different heating rates are reported in Fig. 3. The right shift and the flattening of the crystallization peaks going towards lower heating rates are clearly visible. In fact, when lower heating rates are imposed as test condition, the PPA $571 \mathrm{H}$ sample changes phase quite a lot gradually. Accordingly, the heat generation associated with the phase transition is released in a wide time range and a flatter peak is observed. To the contrary, when progressively higher heating rates are imposed as test condition, the PPA $571 \mathrm{H}$ samples complete their phase transition quicker and quicker. Accordingly, the heat associated with the transition is released in a ever more narrow time range and increasingly sharper peaks are observed.

Starting from collected experimental data, the melting kinetic of PPA $571 \mathrm{H}$ was modelled by using the well-consolidated method of Borchardt and Daniels (BD model) [18]. This method

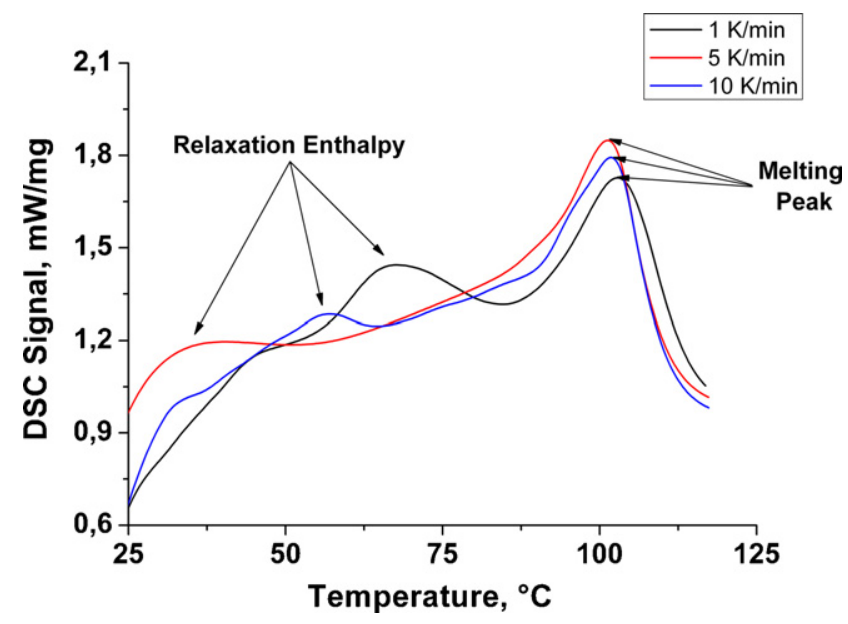

Fig. 2. Dynamic scans at variable heating rates. 


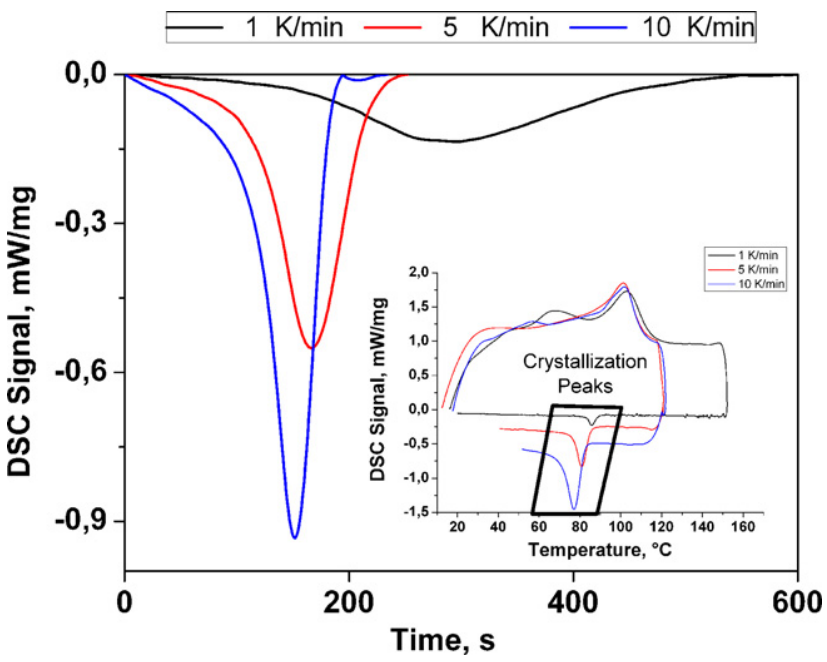

Fig. 3. Crystallization peak of PPA $571 \mathrm{H}$ at different heating rates during DSC testing.

permits to express the melting degree of a thermoplastic polymer as a function of temperature and time as reported hereafter:

$\frac{\mathrm{d} \alpha}{\mathrm{d} t}=K(T)(1-\alpha)^{n}=A \mathrm{e}^{-\left(\Delta E_{\mathrm{a}} / R T\right)}(1-\alpha)^{n}$

where the pre-exponential factor $A$, the reaction order $n$ and the activation energy $\Delta E_{\mathrm{a}}$ are unknown quantities.

Eq. (1) can be rewritten as follows:

$\ln \left(\frac{\mathrm{d} \alpha}{\mathrm{d} t}\right)=\ln A-\frac{\Delta E_{\mathrm{a}}}{R T}+n \ln (1-\alpha)$

The variables $\mathrm{d} \alpha / \mathrm{d} t, 1 / T$ and $1-\alpha$ can be experimentally deduced from the DSC dynamic scans. This way, by multiple regression analysis all the empirical parameters $A, \Delta E_{\mathrm{a}}$ and $n$ can be easily worked out. The values of the BD model parameters are displayed in Fig. 4 together with the trend of $K(T)$ according to $1 / T$ (sketch in the corner of Fig. 4). An Arrhenius trend for $K(T)$ can be confirmed. Solving Eq. (1), the melting degree of the polymeric powders according to time and temperature can be numerically achieved. Fig. 4 reports the melting degree of PPA $571 \mathrm{H}$ according to time and the comparison between experimentally and numerically deduced results. A quite good fitting

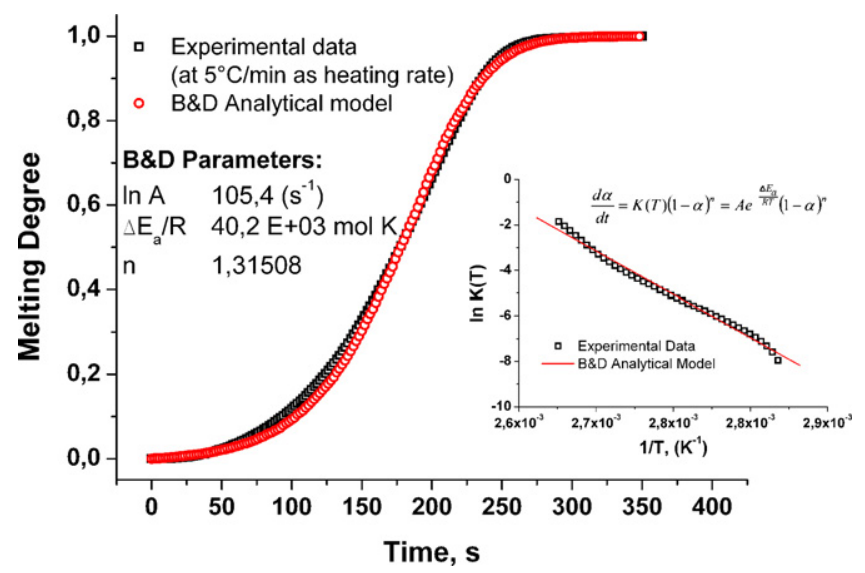

Fig. 4. PPA 571 conversion curve vs. time.

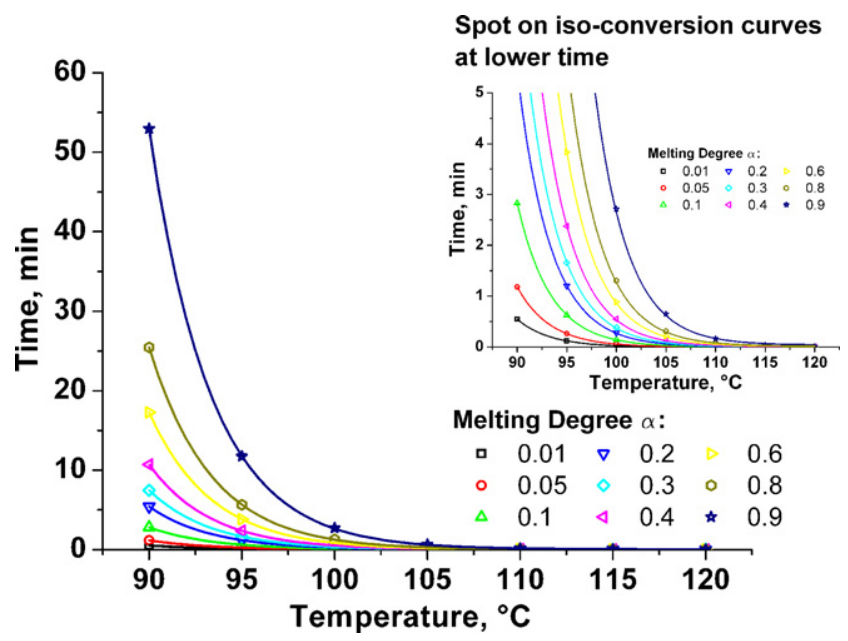

Fig. 5. Iso-conversion curves for PPA $571 \mathrm{H}$ coatings.

can be remarked, thereby stating the higher reliability of the BD model applied to PPA $571 \mathrm{H}$.

By solving Eq. (1) at different temperatures, the trends of isoconversion curves (curves at the same value of melting degree) according to time and temperature can be obtained. Fig. 5 displays the corresponding numerical results. As expected, going towards higher time and temperature faster melting of the polymeric powders is observed. In particular, at temperature as low as $90^{\circ} \mathrm{C}$ (that is, lower than the melting peak point of the PPA $571 \mathrm{H}$ declared by manufacturer and reported in Table 3), almost $1 \mathrm{~h}$ is required to approach to a full melting of the PPA $571 \mathrm{H}$ powders (melting degree of 0.99). To the contrary, at temperature as high as $120^{\circ} \mathrm{C}$ (that is, higher than the melting peak point of the PPA $571 \mathrm{H}$ declared by manufacturer and reported in Table 3), the full melting of the PPA $571 \mathrm{H}$ powders takes place almost instantaneously (see sketch in Fig. 5).

\subsection{Morphological evolution of PPA 571 films}

Fig. 6 displays the trends of the average roughness $R_{\mathrm{a}}$ according to baking time and temperature. As can be seen, increasing

Table 3

Typical properties of the material

\begin{tabular}{lll}
\hline Properties & Standard & Values \\
\hline Specific gravity & - & $0.96 \mathrm{~g} / \mathrm{cm}^{3}$ \\
Tensile strength & ISO 527 & $14 \mathrm{MPa}$ \\
Elongation at break & ISO 527 & $800 \%$ \\
Brittleness temperature & ASTM D-746 & $-78^{\circ} \mathrm{C}$ \\
Hardness & Shore A & 95 \\
Hardness & Shore D & 44 \\
Vicat softening point & ISO 306 & $70^{\circ} \mathrm{C}$ \\
Melting point & - & $105^{\circ} \mathrm{C}$ \\
Tear strength & ASTM D1938 & $22 \mathrm{~N} \mathrm{~mm}^{-1}$ \\
Stress cracking & ASTM D1693 & Greater than $1000 \mathrm{~h}$ \\
Toxicity index & NES 7 & 1.8 \\
Dielectric strength & IEC 243 VDE 0303 & $47.8 \mathrm{kV} / \mathrm{mm}^{\circ}$ at $370 \mu \mathrm{m}$ \\
Volume resistivity & IEC 93 & $3 \times 10^{17} \Omega \mathrm{cm}^{-1}$ \\
Surface resistivity & IEC 93 & $8 \times 10^{17} \Omega$ at $350 \mu \mathrm{m}$ \\
Water absorption & ASTM D570-81 & $<0.03 \%$ \\
\hline
\end{tabular}




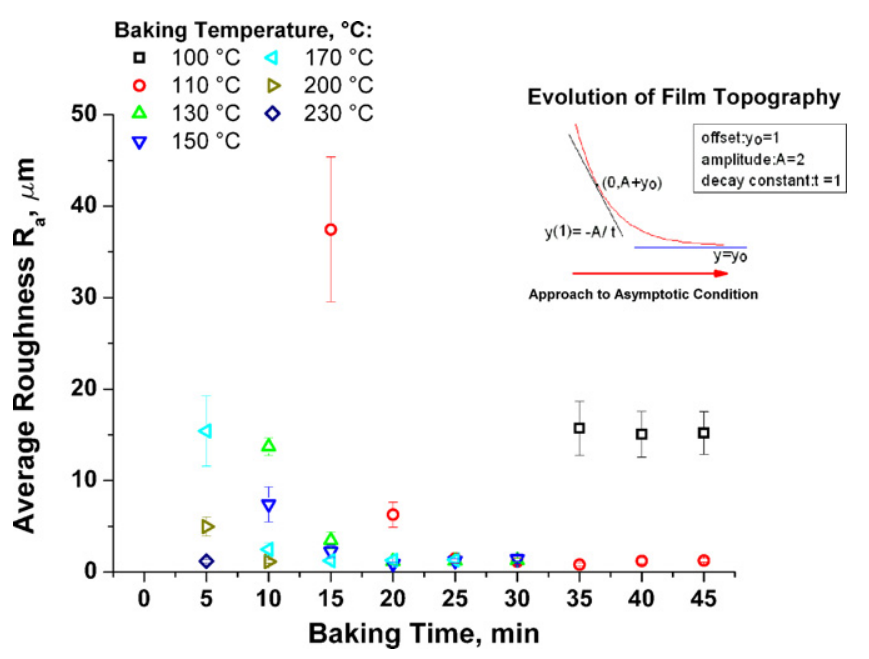

Fig. 6. Average roughness trends of PPA $571 \mathrm{H}$ according to baking temperature and time: first approximation analytical model.
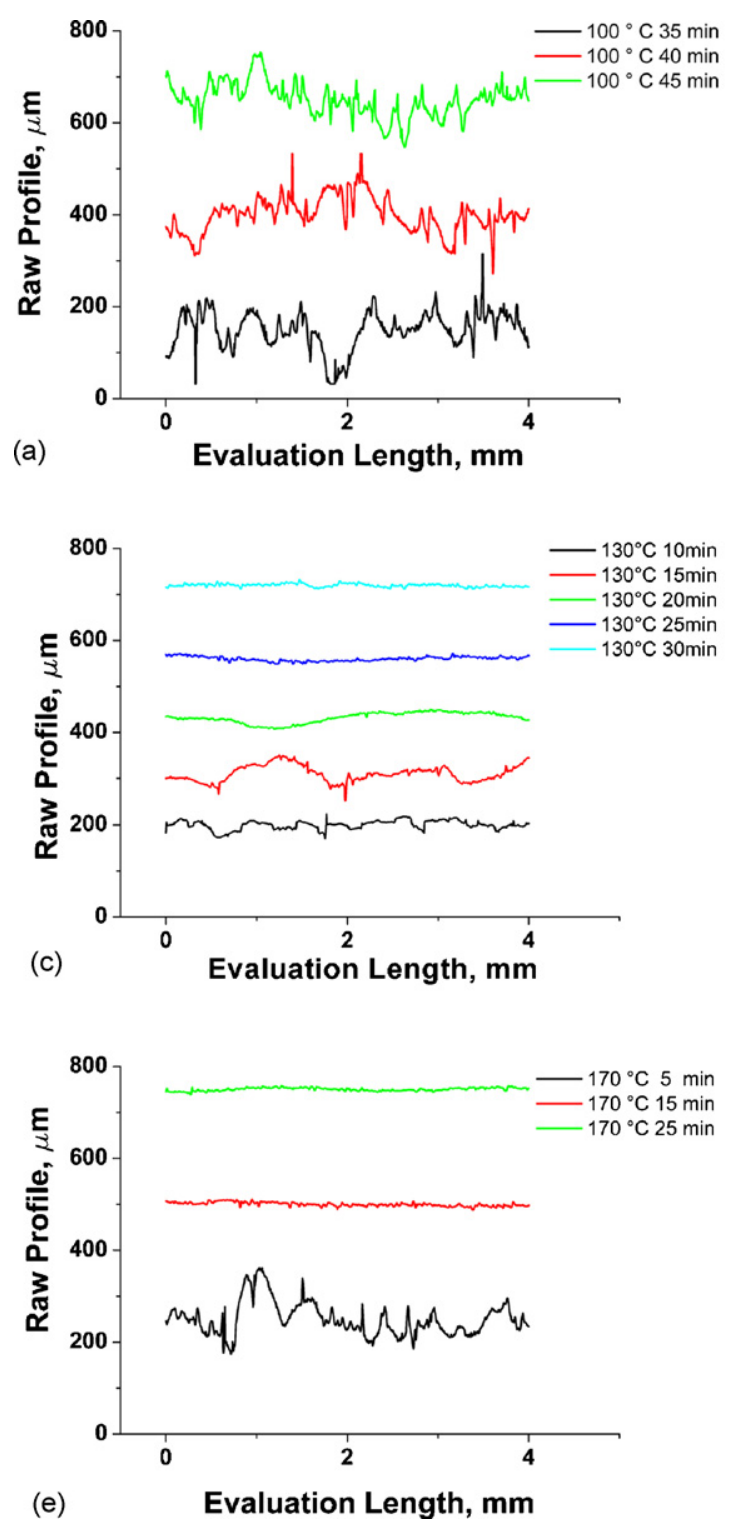

both baking time and temperature, an improvement of surface finish of the polymeric films, that is, a reduction of average roughness $R_{\mathrm{a}}$ values occurs. From experimental findings, a sort of asymptotic condition to best finishing achievable, characteristics of the coating process and coating material as well as of baking temperature, can be deduced. In particular, if too low temperature (that is, lower than peak melting point of PPA 571 $\mathrm{H})$ is set during baking process, the polymeric film does not approach favourable asymptotic conditions. In fact, for $100^{\circ} \mathrm{C}$ as baking temperature, the asymptotic value of the average roughness $R_{\mathrm{a}}$ tends to $15 \mu \mathrm{m}$ even for very long baking time (from 35 to $45 \mathrm{~min}$ ). This result is representative of a highly irregular morphology of the polymeric film after baking process. Watching the raw profiles in Fig. 7(Panel a) and waviness profiles in Fig. 8(Panel a), the steep topography of the films at $100^{\circ} \mathrm{C}$, even for very long baking time, is clearly visible. This results in a film with poor aesthetic aspect due to the bad distension and subsequent poor consolidation of the polymeric film under the
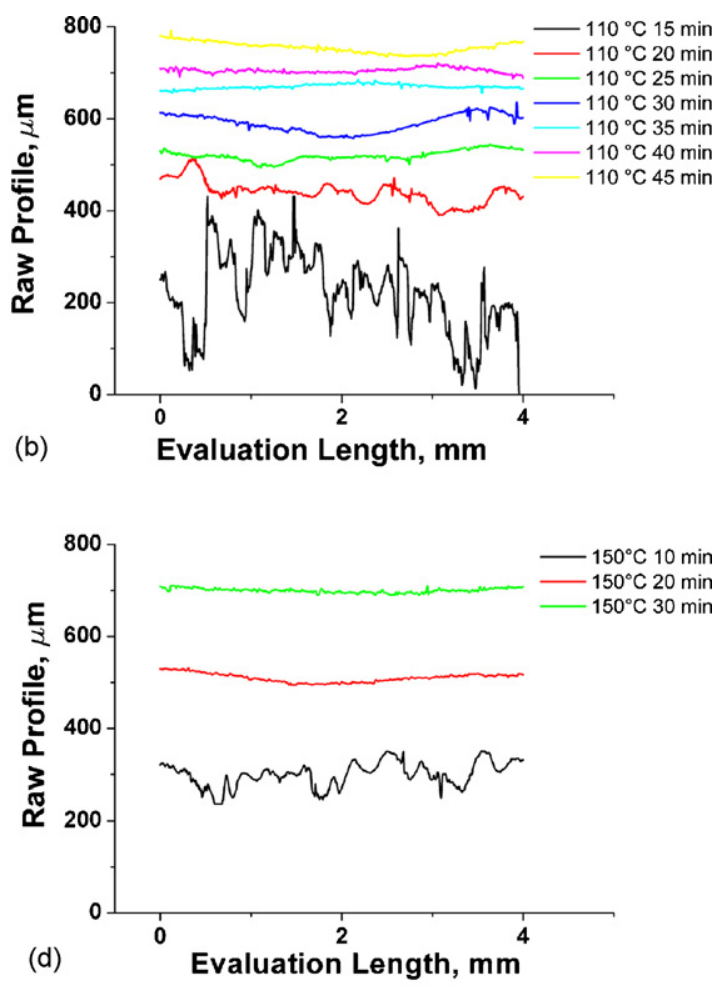

Panel a: Curing Temperature $100^{\circ} \mathrm{C}$ Panel b: Curing Temperature $110{ }^{\circ} \mathrm{C}$ Panel c: Curing Temperature $130{ }^{\circ} \mathrm{C}$ Panel d: Curing Temperature $150{ }^{\circ} \mathrm{C}$ Panel e: Curing Temperature $170{ }^{\circ} \mathrm{C}$

Fig. 7. Roughness profiles measured at different baking times and temperatures. 

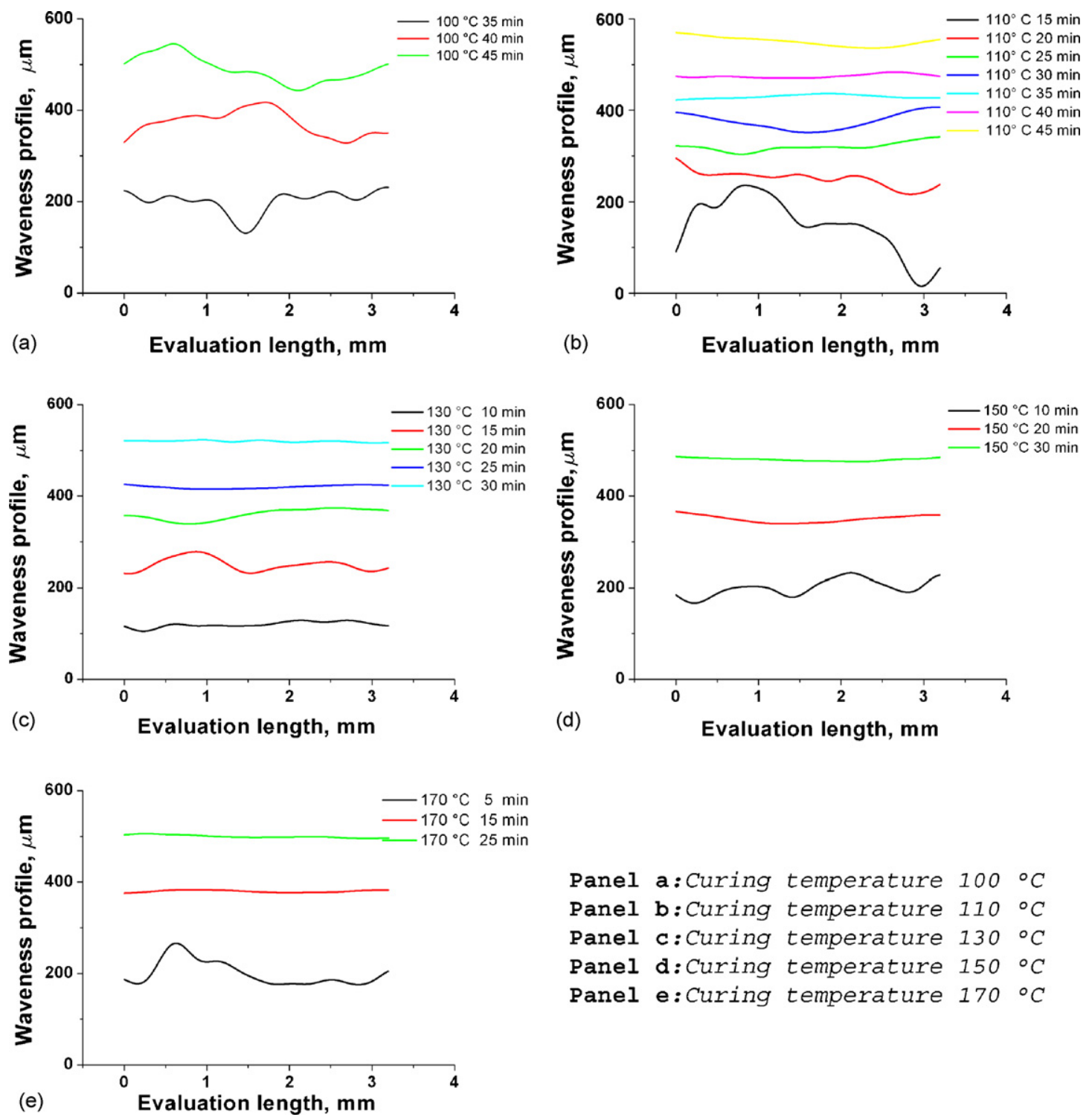

Panel a:Curing temperature $100^{\circ} \mathrm{C}$

Panel b:Curing temperature $110^{\circ} \mathrm{C}$

Panel c:Curing temperature $130{ }^{\circ} \mathrm{C}$

Panel d:Curing temperature $150{ }^{\circ} \mathrm{C}$

Panel e:Curing temperature $170^{\circ} \mathrm{C}$

Fig. 8. Waviness profiles measured at different baking times and temperatures.

prescribed baking conditions. For intermediate values of baking temperatures (from 110 to $200^{\circ} \mathrm{C}$ ), the polymeric films, after different baking times, approach favourable asymptotic conditions for average roughness $R_{\mathrm{a}}$. For each baking temperature, average roughness values around $1.2 \mu \mathrm{m}$ and less are measured. This result is representative of smooth finishes of the polymeric films after baking process. Therefore, if baking temperatures higher than peak melting point of the PPA $571 \mathrm{H}$ are employed, the corresponding polymeric films melt completely and consolidate in the form of uniform and even films. The transitions from irregular finishes to smooth finishes for each baking temperature examined are reported in Fig. 7(Panels b-e) and Fig. 8(Panels b-e) for raw roughness and waviness profile, respectively. Accordingly, an induction time, that is, a time interval each polymeric film needs to approach the asymptotic conditions of average roughness $R_{\mathrm{a}}$ can be deduced from both data reported in Fig. 6 and profiles reported in Figs. 7 and 8. Table 4 approximately reports the values of induction time for each baking temperature in the range of $110-200{ }^{\circ} \mathrm{C}$. As expected, induction time decreases when baking temperatures increase since, in agreement with data reported in Section 3.1, melting phenomena of PPA $571 \mathrm{H}$ are faster, if higher baking temperatures are set. However, if further increases in baking temperature are set (i.e., $230{ }^{\circ} \mathrm{C}$ ), the polymeric film tends to instantaneously melt. In fact, after 5 min as baking time, the average roughness $R_{\mathrm{a}}$ of the film is already worth around $1.2 \mu \mathrm{m}$ and less (Fig. 6), that is,

Table 4

Induction time according to baking temperatures

\begin{tabular}{ll}
\hline Baking temperature $\left({ }^{\circ} \mathrm{C}\right)$ & Induction time $(\mathrm{min})$ \\
\hline 110 & Around $30 \mathrm{~min}$ \\
130 & Around $25 \mathrm{~min}$ \\
150 & Around $20 \mathrm{~min}$ \\
170 & Around $15 \mathrm{~min}$ \\
200 & Around $10 \mathrm{~min}$ \\
230 & Instantaneous
\end{tabular}




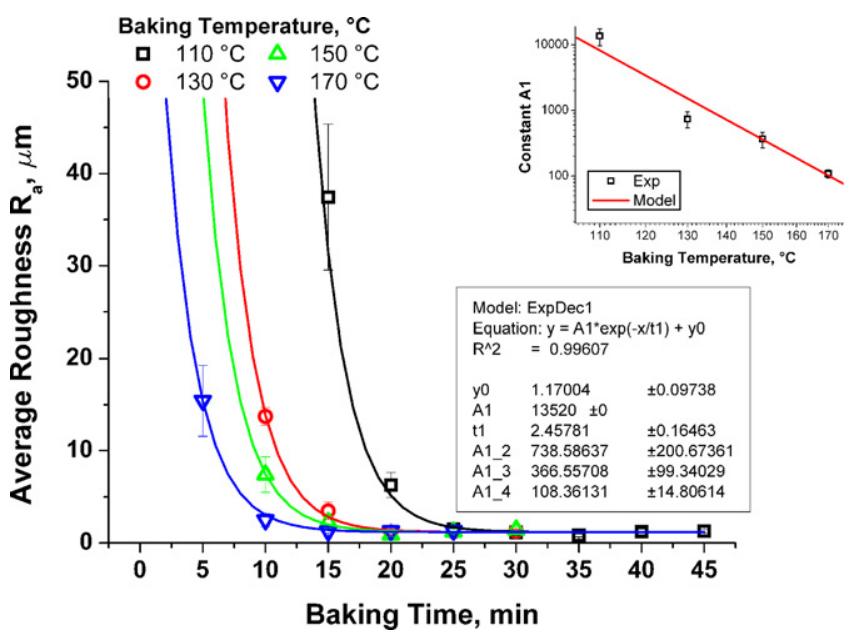

Fig. 9. Average roughness trends of PPA $571 \mathrm{H}$ according to different baking temperatures and times: the analytical model.

the value representative of the best finishes achievable under the prescribed experimental conditions. In such case, no induction time can be defined.

\subsection{Modelling of morphological evolution of PPA 571 films and relationship with powders melting kinetic}

Starting from experimental findings reported in Section 3.2, the average roughness $R_{\mathrm{a}}$ of PPA $571 \mathrm{H}$ can be modelled as a function of baking time and temperature. In particular, the average roughness $R_{\mathrm{a}}$ can be expressed as reported hereafter:

$R_{\mathrm{a}}=A(T) \exp \left(-\frac{t}{t_{1}}\right)+R_{\mathrm{a}}^{0}$

where the pre-exponential function $A(T)$ and parameters $t_{1}$ and $R_{\mathrm{a}}^{0}$ can be deduced by multiple linear regression. Eq. (3) was found to fit very well $\left(R^{2}\right.$ of 0.996$)$ the experimental data available as shown in Fig. 9. Some additional considerations can be done. The pre-exponential function $A(T)$ depends only upon baking temperature, as displayed in the sketch in Fig. 9. Higher the values of baking temperature lower the value of the pre-

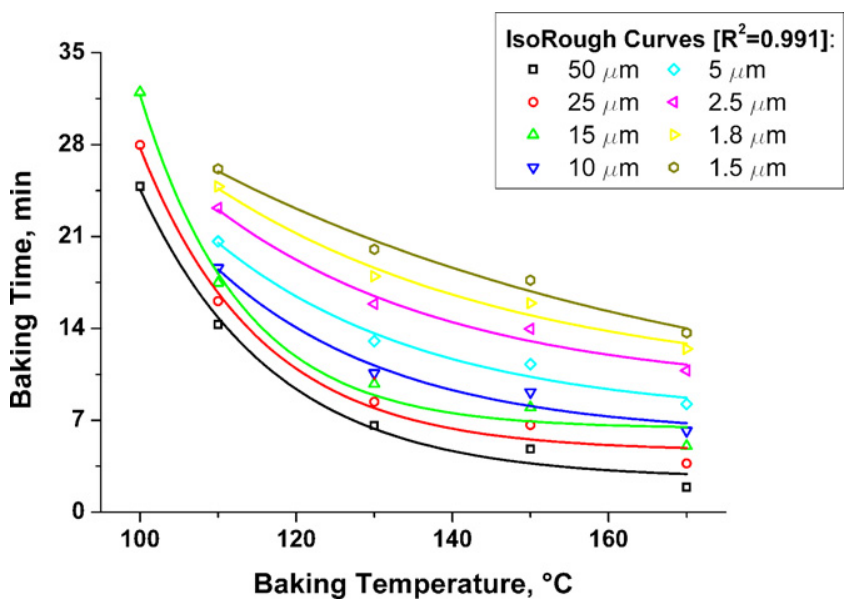

Fig. 10. Iso-roughness curves for PPA $571 \mathrm{H}$ coatings.

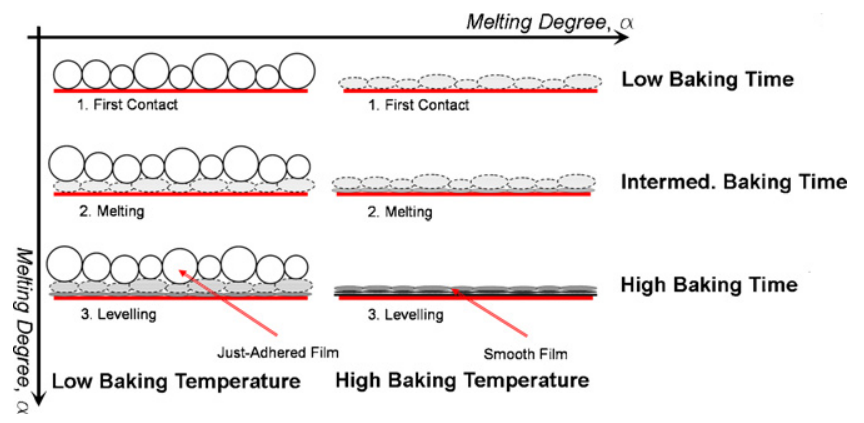

Fig. 11. Interpretation of mechanisms involved in PPA $571 \mathrm{H}$ film built up.

exponential function $A(T)$. Besides, parameters $t_{1}$ and $R_{\mathrm{a}}^{0}$ are invariants with baking temperature and time. Accordingly, they can be considered as model constants, which depend only by the deposition system and operational settings as well as by raw
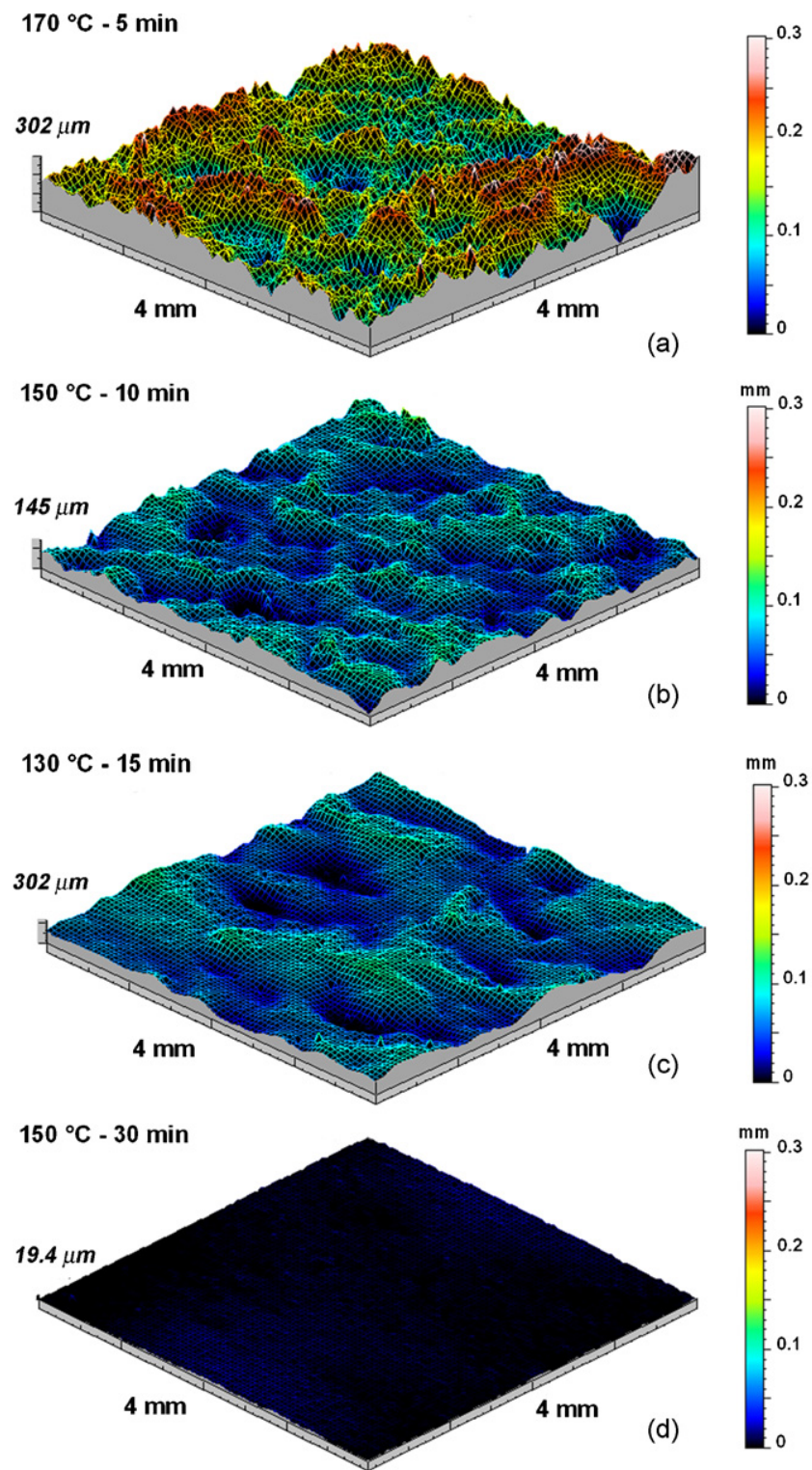

Fig. 12. Surface morphology evolution of the PPA $571 \mathrm{H}$ at different baking temperatures and times. 
materials chosen. Solving Eq. (3) for different baking temperature and time, the iso-roughness curves of EFB deposited PPA $571 \mathrm{H}$ films can be attained. Fig. 10 displays the achieved trends. In Fig. 10, a comparison between analytically calculated data and experimental data is also reported. Even in this case, a quite good fitting ( $R^{2}$ of 0.991$)$ of the proposed analytical solution can be claimed.

In agreement on what has just been mentioned in Section 3.2 , a useful physical interpretation of the proposed model can be provided. Being parameters $t_{1}$ and $R_{\mathrm{a}}^{0}$ invariants, Eq. (3) can be considered as a mono-parametric model, where the approach of average roughness $R_{\mathrm{a}}$ to its asymptotic value $R_{\mathrm{a}}^{0}$ is handled only by the values of pre-exponential function $A(T)$, that is, by baking temperatures. As said, for low values of baking temperatures, the factor $A(T)$ assumes high values. Consequently, the block $A(T) \exp \left(-t / t_{1}\right)$ reduces to 0 even for low values of baking time $t$, being the pre-exponential factor very high. The value of baking time, which reduces to zero the block $A(T) \exp \left(-t / t_{1}\right)$, that is, which makes $R_{\mathrm{a}}$ approach $R_{\mathrm{a}}^{0}$ is, literally, the value of the induction time.

The results provided from the solution of the analytical model are in good agreement with thermal behaviour of PPA $571 \mathrm{H}$. In fact (as seen in Section 3.1), fast approaches of PPA 571 $\mathrm{H}$ powders to higher melting degree can be achieved only if higher temperatures are set (see sketch in Fig. 5). To the contrary, if low temperatures are set, PPA $571 \mathrm{H}$ melting process proceeds slowly, that is, higher melting degree can be achieved only after long time (see Fig. 5). Accordingly, the achievement of smooth finishes of the polymeric films is quicker if higher baking temperatures are set, as faster melting of PPA $571 \mathrm{H}$ on the metal substrate during baking occurs, with resulting shorter induction time. To the contrary, the settings of lower baking temperature cause slower melting process of PPA $571 \mathrm{H}$ on the metal substrate during baking, with resulting higher induction time.
Fig. 11 exemplifies all the mechanisms involved during PPA $571 \mathrm{H}$ film built up. The onset of molten plastic layer and the concurrent film formation is a critical phase and can be broken down into major steps in agreement with the indications reported in the literature [17,19]: first, the powder particles, just electrostatically adhered on the metal surface after EFB coating process, can split in melting coalescence. As a result of the coalescence process, the polymeric film is formed and, then, if enough heat is provided to the coating during baking process, the polymeric film melts and gets levelled. Subsequently, the new coating surface is established (Fig. 11). Nonetheless, thermally driven powder melting is extremely sensitive to baking temperature. In fact, if baking temperature is below a critical value (i.e., below the peak melting point of PPA $571 \mathrm{H}$ ), the heat transferred to the just adhered polymeric powders is not enough to complete all the transformations phases, and the powder particles are able only to complete the first phase (i.e., the coalescence) as reported in Fig. 11 (for low baking temperature). This phenomenon causes the build-up of a coating characterized by a very irregular and uneven surface morphology in agreement with results coming from our roughness measurements. On the other hand, if baking temperature is above the critical value (i.e., above the peak melting point of PPA $571 \mathrm{H}$ ), the polymeric film can complete the transformation phases and achieves the characteristic of a proper coating, hence exhibiting a smooth and uniform finish. Of course, higher the baking temperature, faster the melting process of PPA $571 \mathrm{H}$, lower the baking time needed for the establishment of the smooth finishes of the polymeric films in agreement with the typical thermal behaviour of PPA $571 \mathrm{H}$ powders.

\subsection{Analysis of 3D morphology of PPA 571 films}

Fig. 12 reports significant 3D surface morphologies of PPA $571 \mathrm{H}$ films in different baking conditions. All the different
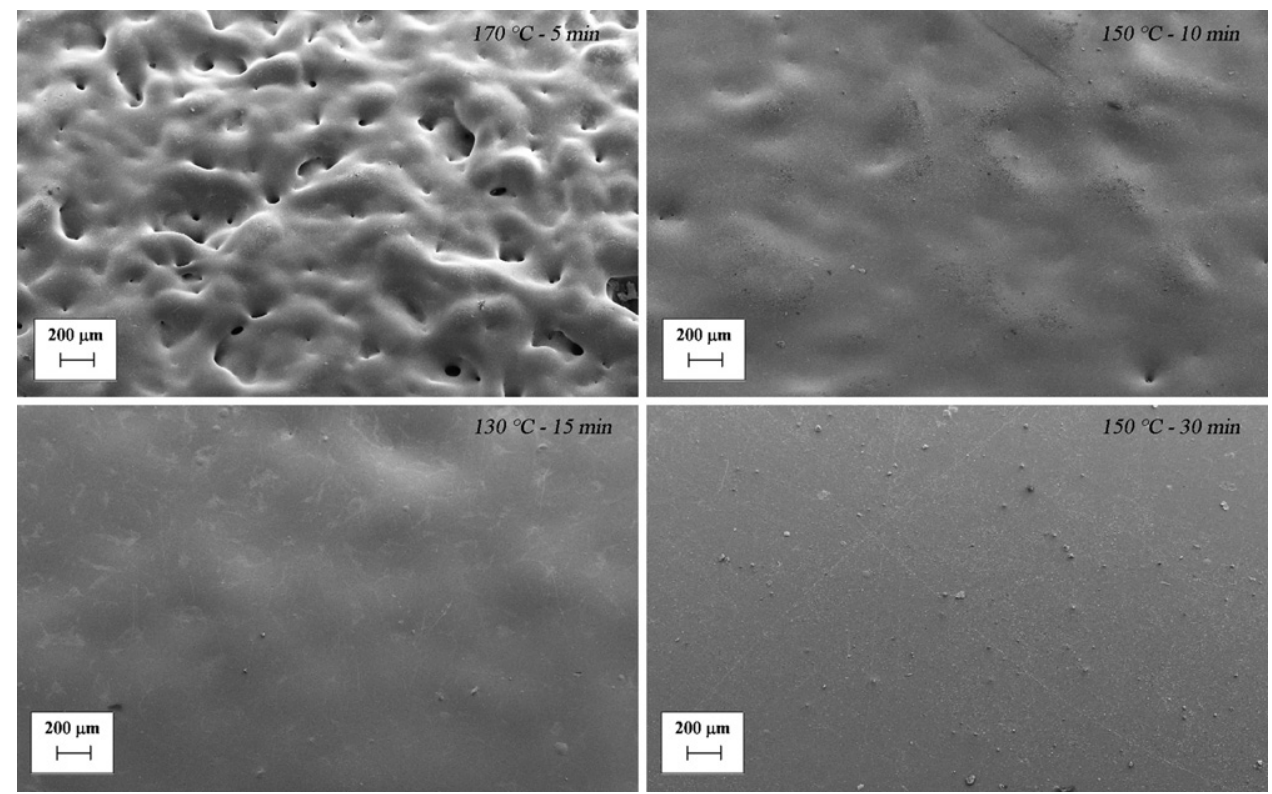

Fig. 13. SEM analysis of PPA $571 \mathrm{H}$ coatings at different baking temperatures and times. 


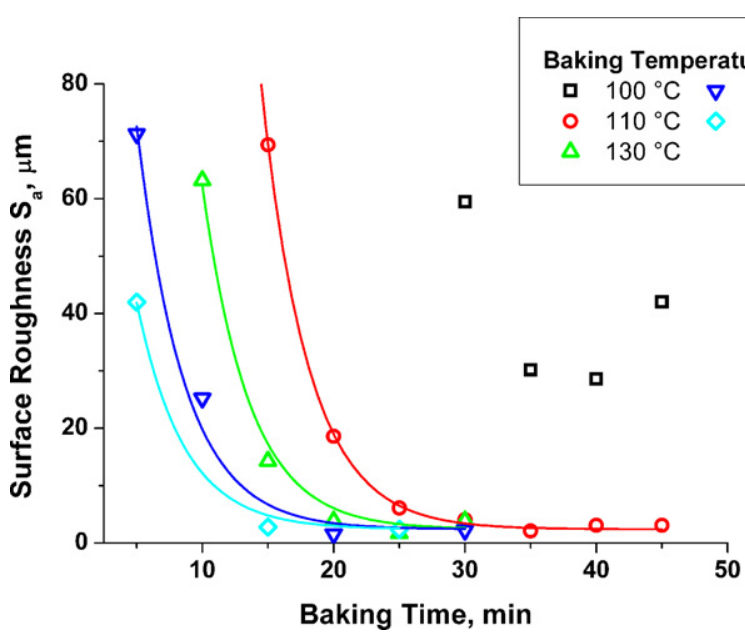

Fig. 14. Surface roughness of PPA $571 \mathrm{H}$ coatings measured at different baking temperatures and times.

phases of PPA $571 \mathrm{H}$ film built up are well represented in Panels $\mathrm{a}-\mathrm{d}$ of Fig. 12. Panel a is representative of an incipient melting coalescence phase. The map is referred to $170^{\circ} \mathrm{C}$ as baking temperature and just $5 \mathrm{~min}$ as baking time: a too short time for the establishment of the full film structure. The form of the individual powder grains is still visible. Panels $b$ and $c$ are representative of two different stages of the levelling phase. They refer to intermediate baking conditions for both baking time and temperature (respectively, $150^{\circ} \mathrm{C}-10 \mathrm{~min}$ and $130^{\circ} \mathrm{C}-15 \mathrm{~min}$ ). As can be seen from watching the surface morphologies, the levelling of the polymeric film produces the disappearance of the individual powder grains, which melt together up to form a semi-continuous and almost uniform film. Panel d is representative of the final stage of the transformation process, which brings the EFB deposited powders to a form of a full consolidated, uniform and continuous film. The achieved smooth finish of the polymeric film and its evenness is clearly visible in Fig. 12.

SEM analysis reported in Fig. 13 confirms the above considerations, with the evolution of the polymeric film from the status of loose powders to the status of a full consolidated smooth film through different levelling stages being clearly visible. Accordingly, Fig. 14 displays the trend of 3D surface roughness $S_{\mathrm{a}}$ according to baking temperature and time. A continuous decreasing trend in surface roughness $S_{\mathrm{a}}$ is observed going toward higher baking time and temperature. This result is in agreement with both indications provided in Sections 3.1 to 3.3 and 3D morphological evolutions as hereby reported.

\section{Conclusions}

Experiments were carried out on AISI 1040 components coated with PPA $571 \mathrm{H}$ by using an electrostatic fluidized bed system (EFB). In this work, some results related to the understanding of thermal behaviour of the PPA $571 \mathrm{H}$ powders and to the interrelationship between thermal behaviour of PPA 571 $\mathrm{H}$ and final morphology of the EFB deposited polymeric films after baking were reported.
Form standard calorimetric analysis, the thermal behaviour of PPA $571 \mathrm{H}$ powders was full understood and some experimental results are reported hereafter: (i) the melting kinetic of PPA 571 $\mathrm{H}$ powders was experimentally deduced and modelled by $\mathrm{BD}$ method; (ii) the melting degree of PPA $571 \mathrm{H}$ powders was reported in the form of 'iso-conversion' curves versus testing temperature and time; (iii) higher melting degrees are quickly achieved if higher temperatures are set.

From coating tests and film morphological characterization, the coating capability of the EFB system was definitely verified. Baking process was found to be of fundamental importance for the polymeric films built up and the establishment of the related properties. In particular, from average roughness trends, a standard working condition (baking temperature and time) able to produce smooth finishes of PPA $571 \mathrm{H}$ polymeric films can be deduced. In such a scenario, from experimental tests performed employing different baking time and temperatures, it can be deduced: (i) the improvement in surface roughness and waviness of PPA $571 \mathrm{H}$ films is related to chosen baking time and temperature; (ii) during baking process, roughness parameters of PPA $571 \mathrm{H}$ films tends to approach a characteristic asymptotic condition representative of the best finishes under that experimental set up; (iii) an induction time, defined as the time interval needed for the average roughness $R_{\mathrm{a}}$ of the polymeric film to approach its asymptotic condition, was found to be strictly dependent on baking time and temperature; (iv) an improvement of average roughness $R_{\mathrm{a}}$ to values as small as $1 \mu \mathrm{m}$ can be quickly attained (low induction time), if baking temperatures as high as $170^{\circ} \mathrm{C}$ and over are set; (v) an improvement of average roughness $R_{\mathrm{a}}$ to values as small as $1 \mu \mathrm{m}$ would be slowly attained (high induction time) if baking temperatures lower than $170^{\circ} \mathrm{C}$ are set; (vi) the full establishment of the PPA $571 \mathrm{H}$ film structure cannot be attained, if baking temperatures lower than peak melting point of the resin (i.e., $105^{\circ} \mathrm{C}$ ) are set; (vii) finally, the establishment of a progressively more regular surface morphology is stated by confocal and scanning electron microscopy and surface parameters $S_{\mathrm{a}}$ follows the same trend of roughness parameters.

Based upon experimental findings, a comprehensive monoparametric analytical model was defined to interpret the trend of average roughness $R_{\mathrm{a}}$ according to baking parameters. A standard exponential decay function of the average roughness $R_{\mathrm{a}}$ versus baking time with a pre-exponential factor dependent only on baking temperature was chosen as analytical model. The good fitting between the numerical and the experimental data confirms the model reliability and its suitability as first instruments to provide useful indications to the powder coaters on how to best deal with settings of baking temperature and time.

\section{References}

[1] J.F. Richardson, Incipient fluidization and particulate systems, in: J.F. Davidson, D. Harrison (Eds.), Fluidization, Academic Press, New York, 1971.

[2] Faith Reidenbach, ASM Metal Handbook, vol.5, Surface Engineering, 10th ed., ASM International, 1994.

[3] D.S. Richart, A report on the fluidized-bed coating system. Part 1. Fluidized bed variables and their influences, Plastics Des. Tech. 2 (1962) 18-26. 
[4] D.S. Richart, A report on the fluidized-bed coating system. Part 2. Plastics for coating and their selection, Plastics Des. Tech. 2 (1962) 26-34.

[5] C.K. Pettigrew, Fluidized bed coating. Part 1. Effects of fluidized bed variables, substrate pretreatment and preheating method, Mod. Plastics 44 (1966) 111-117.

[6] C.K. Pettigrew, Fluidized bed coating. Part 2. Effects of dipping, postheating and complex geometrical variables, Mod. Plastics 44 (1966) 150-156.

[7] M.R. Strucaly, Electrostatic Powder Coating for Armature Impregnation, Electrostatic Technology Inc., Branford, Connecticut, USA, 1977.

[8] F.S. Ali, I.I. Inculet, Modelling of electric fields during electrostatic coating of metallic substrate in fluidized beds, IEEE Trans. Ind. Appl. 36 (5) (2000).

[9] F.S. Ali, I.I. Inculet, Electric field analysis of the tribocharged fluidized bed powder coating process, IEEE Trans. Ind. Appl. 36 (5) (2000).

[10] K.C. Leong, G.Q. Lu, V. Rudolph, A comparative study of the fluidizedbed coating of cylindrical metal surfaces with various thermoplastic polymer powders, J. Mater. Process. Technol. 89-90 (1999) 354360.

[11] K.C. Leong, G.Q. Lu, V. Rudolph, Modelling of heat in fluidized bed coating of cylinder, Chem. Eng. Sci. 56 (2001) 5189-5200.
[12] K.C. Leong, G.Q. Lu, V. Rudolph, An upper bound solution for the coating thickness of cylinders in a fluidized bed, Chem. Eng. Sci. 54 (8) (1999) 1145-1149.

[13] K.C. Leong, G.Q. Lu, V. Rudolph, The effect of latent heat of fusion on heat transfer in fluidized-bed coating of thin plates, Chem. Eng. Process. 41 (7) (2002) 567-576.

[14] M. Barletta, V. Tagliaferri, Electrostatic fluidized bed deposition of a high performance polymeric powder on metallic substrates, Surf. Coat. Technol. 200 (14-15) (2006) 4282-4290.

[15] M. Barletta, V. Tagliaferri, Influence of process parameters in electrostatic fluidized bed coating, Surf. Coat. Technol. 200 (14-15) (2006) 4619-4629.

[16] M. Barletta, G. Simone, V. Tagliaferri, Advance in fluidized bed coating: an experimental investigation on a performance polymer coating alloy, J. Mater. Process. Technol. 178 (1-3) (2006) 170-180.

[17] M. Barletta, G. Simone, V. Tagliaferri, A FEM model of conventional hot dipping coating process by using a fluidized bed, Prog. Org. Coat. 54 (4) (2005) 390-398.

[18] R.B. Prime, Thermal Characterization of Polymeric Materials, Academic Press, New York, 1981.

[19] S.S. Lee, H.Z.Y. Han, J.G. Hilborn, J-A.E. Manson, Prog. Org. Coat. 36 (1999) 79-88 